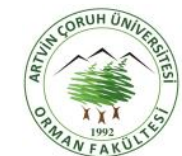

\title{
Dendroctonus micans (Kugelann) (Coleoptera: Curculionidae)'ın Artvin ladin ormanlarındaki güncel populasyonunun ve Rhizophagus grandis Gyllenhal (Coleoptera: Monotomidae)'in istila oranın araştırılması
}

\author{
Investigation of the current population of Dendroctonus micans (Kugelann) (Coleoptera: Curculionidae) and \\ colonization rate of Rhizophagus grandis Gyllenhal (Coleoptera: Monotomidae) in spruce forests of Artvin
}

Hazan ALKAN AKINCI

Artvin Çoruh Üniversitesi, Orman Fakültesi, Orman Mühendisliği Bölümü, Artvin, Türkiye

Eser Bilgisi / Article Info

Araştırma makalesi / Research article DOI: 10.17474/artvinofd.285135

Sorumlu yazar / Corresponding author

Hazan ALKAN AKINCI

e-mail: hazan.akinci@artvin.edu.tr

Geliş tarihi / Received

10.01.2017

Düzeltme tarihi / Received in revised form

23.02.2017

Elektronik erişim / Online available

27.03.2017

Anahtar kelimeler:

Kabukböceği

spesifik predatör

böcek zararı

Keywords:

Bark beetle

specific predator

pest damage

\begin{abstract}
Özet
Bu çalışmada Dendroctonus micans (Kugelann) (Coleoptera: Curculionidae)'ın Artvin doğu ladini (Picea orientalis (L.) Link.) ormanlarındaki güncel populasyonu ve spesifik predatörü Rhizophagus grandis Gyllenhal (Coleoptera: Monotomidae)'in böceğin galerilerini istila durumu araştırılmıştır. Arazi çalışmalarında, toplam 30 örnekleme alanı ve 20 transektte çalışılmıştır. Örnekleme alanları $30 \times 10 \mathrm{~m}$ boyutlarında ve transektler de $50 \mathrm{~m}$ uzunluğundadır. Günümüzde, D. micans'ın Artvin ladin ormanlarında "çok düşük istila" oranına sahip olduğu ve böceğin ağaçlardaki istila yüzdesinin 2000'li yılların başına oranla 4.1 kat azaldığı tespit edilmiştir. Meşcere kenarında bulunan ağaçlar meşcere içine göre daha fazla böcek zararına uğramıştır. $D$. micans'ın larva galerilerinin tamamında $R$. grandis tespit edilmiştir. Böceğin ormanlardaki zararı düşük seviyede olduğunda da R. grandis'in avının larva galerine yerleşebildiği tespit edilmiştir.
\end{abstract}

\begin{abstract}
In this study, current population of Dendroctonus micans (Kugelann) (Coleoptera: Curculionidae), and colonization status of its specific predator Rhizophagus grandis Gyllenhal (Coleoptera: Monotomidae) in oriental spruce (Picea orientalis (L.) Link.) forests of Artvin were investigated. Field works were conducted in a total of 30 sampling plots and along 20 transects. Sampling plots were $30 \times 10 \mathrm{~m}$ in size and transects $50 \mathrm{~m}$ long. Presently, D. micans has a "very low infestation" rate in Artvin spruce forests and $D$. micans infestation rate is 4.1 times lower than the early 2000s. The trees at the stands edges were attacked more than trees in stand closure. All the larval galleries of $D$. micans were colonized by $R$. grandis. $R$. grandis could colonize larval galleries of its prey even in endemic conditions.
\end{abstract}

\section{GiRiş}

Avrupa ve Asya'da ladinin (Picea spp.) başlıca zararlılardan biri olan Dendroctonus micans (Kugelann) (Coleoptera: Curculionidae), yayılış gösterdiği ülkelerde klimatik ve orman şartlarına çok iyi adapte olmuş ve milyonlarca ağacın kurumasına yol açmıştır (Grégoire 1988; Fielding ve Evans 1997; Alkan-Akıncı ve ark. 2009). Türkiye'de Doğu Karadeniz Dağları ve Gürcistan'da Kafkas Dağlarında doğal yayılışa sahip olan doğu ladini, Picea orientalis (L.) Link. ormanlarındaki varlığı ilk kez 1957 yılında Gürcistan'da kaydedilmiştir (Khobakhidze ve ark. 1970). Ardından 1966 yılında Posof'ta Gürcistan sınırına komşu meşcerelerde tespit edilmiştir (Acatay 1968). D. micans günümüzde Türkiye'deki ladin ormanlarının neredeyse tamamına yerleşmiştir (Alkan-Akıncı ve ark. 2014).

Dendroctonus micans'a karşı 1966-1971 yıllarında mekanik mücadele, 1972-1985 yıllarında kimyasal mücadele uygulanmıştır (Aksu 2011). Uygulanan bu mücadele çalışmalarına rağmen böceğin Artvin ladin ormanlarının tamamına yayılması önlenememiştir ve 1985 yılında böceğe karşı biyolojik mücadele çalışmaları başlatılmıştır. D. micans'a karşı türün spesifik predatörü olan Rhizophagus grandis Gyllenhal (Coleoptera: Monotomidae) laboratuarlarda üretilerek ormanlardaki böcekli ağaçlara yerleştirilmiştir. Predatörün üretim çalışmaları, Artvin Orman Bölge Müdürlüğü bünyesinde kurulan 14 adet küçük ölçekli yetiştirme laboratuarlarında 
gerçekleştirilmiştir (Alkan 1989, 2000; Aksu 2011). Bugüne kadar, 5 milyondan fazla predatör böcek zararı devam eden ağaçlara yerleştirilmiştir. Artvin ve Giresun'daki D. micans populasyonu 2009 yilından buyana endemik düzeydedir ve bu alanlara yırtıcı salınmasına son verilmiştir (Eroğlu vd. 2010; Aksu ve ark. 2014).

Rhizophagus grandis'in D. micans'ın zarar yaptığı meşcerelere doğal yoldan ulaşması zaman aldığından, predatörün yetiştirilerek böcek zararının devam ettiği ağaçlara yerleştirilmesi biyolojik mücadele açısından önem taşımaktadır. D. micans salgınlarının yaşandığı alanlarda, $R$. grandis'in ilk defa tespit edilmesi, Hollanda'da 15 yıl, Belçika'da ise 50 yıl sonra olmuştur (Grégoire 1988). Türkiye'de ise 1980 'li yıllarda, Gürcistan sınırına yakın meşcerelerde yaklaşık 12000 ha'lık bir alanda doğal olarak bulunduğu tespit edilmiştir (Serez ve ark. 1987). D. micans'ın ilk tespit edildiği günden $R$. grandis'in böceğin yayılış alanının bir kısmında tespit edildiği güne kadar, yoğun populasyona sahip $D$. micans, ormanlarımızda önemli ekonomik kayıplara neden olmuştur. Böceğin saldırı oranının hektarda 20 ağaç olduğu durumlar "yoğun istila" ve 5 'ten az olduğu durumlar "çok düşük istila" olarak kabul edilmektedir (Grégoire 1984; Grégoire ve ark. 1989).

Dendroctonus micans'ın, Artvin ve Giresun ormanlarında 1990'lı yılların başında ladin ağaçlarının \%36'sına zarar verdiği ve bunların \%25'inde zararını sürdüğünü belirtilmiştir (Eroğlu 1995). Artvin, Trabzon ve Giresun'da 2001 - 2004 yıllarında, ladin ağaçlarının \%21.7'sine saldırdığı ve saldırıya uğrayan ağaçların \%11.1'inde de aktif olduğu kaydedilmiştir (Alkan-Akıncı 2006). Aynı çalışmada, sadece Artvin ve ilçelerini kapsayan arazi çalışmalarında, toplam 17 örnekleme alanında çalışıldığı, bu örnekleme alanlarının tamamında $D$. micans'ın faaliyetinin devam ettiği ağaçların ve $R$. grandis'in bulunduğu kaydedilmiştir. Artvin ve ilçelerindeki 17 örnekleme alanında, toplam 491 ladin ağacı incelenmiş, bunlardan 56 (\%11.4)'sında böceğin zararının devam ettiği ve zararın devam ettiği ağaçlardan 23 (\%41.1)'ünde de $R$. grandis'in bulunduğu belirtilmiştir. Sadece Artvin Orman işletme Müdürlüğü bünyesindeki ormanlarda gerçekleştirilen arazi çalışmalarında, 7 örnekleme alanında toplam 166 ağacın değerlendirildiği, bunlardan 21 (\%12.7)'inde $D$. micans zararının devam ettiği ve bu ağaçlardan 12 (\%57.1)'sinde de böceğin predatörünün bulunduğu kaydedilmiştir (Alkan-Akıncı 2006).

Rhizophagus grandis'in D. micans'ın yoğunluğuna bağlı sayısal tepkisi olduğu kaydedilmektedir. Belçika'daki endemik şartlar altında $R$. grandis'in $D$. micans galerilerinin $\% 60$ 'ını istila ettiği, salgın sırasında ise $D$. micans galerilerinin \%78'e kadarının istila edildiği bilinmektedir (Grégoire 1988).

Rhizophagus grandis, D. micans'la mücadelenin önemli bir bileşeni olarak kabul edilmektedir. Laboratuar çalışmalarına göre, bir haftalık süre sonunda bir çift ergin $R$. grandis'in, yeni çıkan $D$. micans larvalarının tamamını tüketmektedir (King ve ark. 1991). Bir çift $R$. grandis ergini ve bunların yavrularının, III. dönem $D$. micans larvalarının bulunduğu galeri sisteminde, $D$. micans genç erginlerinin oluşmasını 2/3 oranında azalttığı bilinmektedir (Grégoire 1985; Grégoire ve ark. 1989).

Konukçu ağacın doğu ladini olduğu laboratuar çalışmalarında, bir çift $R$. grandis'in yavrularının bir haftada $D$. micans galeri sisteminin yarısından fazlasını, ikinci ve üçüncü haftada ise neredeyse tamamını tükettiği kaydedilmiştir. $R$. grandis'in avı üzerinde önemli bir sınırlayıcı etken olduğu vurgulanmıştır (Alkan-Akıncı ve Grégoire 2016).

Bu çalışmada, D. micans'ın Artvin doğu ladini ormanlarındaki güncel populasyonun araştırılması ve $R$. grandis' in bu böceğin galerilerini istila durumunun ortaya koyulması amaçlanmıştır. Bulgular aynı mevkilerde daha önce yapılan araştırma sonuçlarıyla karşılaştırılmıştır. Elde edilen verilerle $D$. micans' in ve $R$. grandis'in Artvin'deki uzun dönemli seyrinin ve populasyon etkileşimlerinin ortaya koyulmasına katkı sağlanacaktır.

\section{MATERYAL VE YÖNTEM}

\section{Çalışma sahası}

Çalışma 2014 ve 2015 yıllarının Temmuz ve Ağustos aylarında Artvin Orman İşletme Müdürlüğü (OiM)'ne bağlı ormanlarda gerçekleştirilmiştir. Arazi çalışmaları, 1240 1800 m rakımlarda bulunan, Kafkasör, Mersivan, 
Cerattepe ve Taşlıca'daki saf ladin veya ladinin baskın tür olduğu karışık meşcerelerde yürütülmüştür.

\section{Veri toplama}

Toplam 30 örnekleme alanı ve 20 transektte bulunan ladin ağaçları değerlendirilmiştir. Arazi çalışmalarının yürütüldügü örnekleme alanları $30 \times 10 \mathrm{~m}$ boyutlarında ve transektler de $50 \mathrm{~m}$ uzunluğundadır. Örnekleme alanlarında, örnekleme alanının sınırı içindeki ladin ağaçlarında $D$. micans zararı olup olmadığı, böceğin zararının görüldüğü ağaçlardaki galerilerde bulunan değişik gelişim basamaklarındaki $D$. micans sayısı ve bu galerilerde varsa böceğin spesifik pradetörü olan $R$. grandis'in değişik gelişim basamaklarındaki birey sayısı kaydedilmiştir. Alınan transektlerde, $50 \mathrm{~m}^{\prime}$ lik bir hat boyunca ilerlenerek $D$. micans zararı görülen ağaçlar, bu ağaçlarda gelişmekte olan $D$. micans ve varsa $R$. grandis sayıları kaydedilmiştir. Çalışılan örnekleme alanlarından 20 tanesi ve transektlerden de 10 tanesi meşcere kenarında bulunmaktadır.

\section{İstatistik Analizler}

Veriler IBM SPSS 19.0 programı kullanılarak analiz edilmiştir. T testi uygulanarak, çalışma yılları, örnekleme alanları ve transektler, meşcere kenarında ve meşcere kapalılı̆ı içinde bulunan ağaçlar arasında $D$. micans zararının devam ettiği ağaç sayısı bakımından fark olup olmadığı belirlenmiştir.

\section{BULGULAR}

Çalışma kapsamında toplam 1265 ladin ağacı değerlendirilmiştir. Bu ağaçlardan 451 ve 456'sı sırasıyla 2014 ve 2015 yıllarında çalışılan örnekleme alanlarında, 176 ve 182 'si ise sırasıyla 2014 ve 2015 yıllarında çalışılan transktlerde incelenmiştir.

Örnekleme alanlarının 20 (\%66.7)'sinde ve transektlerin de $9(\% 45)^{\prime}$ unda $D$. micans'ın zararının devam ettiği ağaçlar bulunmaktadır. Örnekleme alanları ve transektlerde, D. micans zararının devam ettiği ağaçlar arasındaki fark istatistiksel olarak anlamlıdır (t: 2.046, df: 48, $P<0.05)$. Örnekleme alanlarının 5 (\%16.7)'inde $R$. grandis tespit edilmiştir. Transektlerde ise böceğin predatörüne rastlanmamıştır.

Çalışmanın ilk yılında incelenen 627 ağaçtan 21 (\%3.3)'inde $D$. micans'ın zararının olduğu, bu ağaçlardan da 3 (\%14.3)'ündeki $D$. micans galerilerinde $R$. grandis tespit edilmiştir. 2015 yılında ise 638 ağaçtan 18 (\%2.8)'inde böceğin zararının olduğu ve bu ağaçlardan 2 (\%11.1)'sinde böceğin galerilerinde $R$. grandis bulunduğu belirlenmiştir. Çalışmanın yapıldığı yıllar arasında, $D$. micans zararının devam ettiği ağaç sayısı arasındaki fark istatistiksel olarak anlamlı değildir (t: 0.516, df: 48, $P$ > 0.05). Toplam 1265 ağaçtan 39 (\%3.1)'unda D. micans'ın faaliyetinin devam ettiği, bu ağaçlardan 5 (\%12.8)'inde $R$. grandis bulunduğu belirlenmiştir (Tablo 1 ).

Meşcere kenarında bulunan örnekleme alanlarında ve transektlerde toplam 809 ağaç incelenmiştir. Bu ağaçlardan 35 (\%4.3)'inde $D$. micans'ın faaliyetinin devam ettiği ve 5 (\%14.3) ağaçtaki $D$. micans galerilerinde $R$. grandis bulunduğu saptanmıştır. Meşcere kapalılığı içinde yer alan örnekleme alanlarında ve transektlerde toplam 456 ağaç değerlendirilmiştir. Bu ağaçlardan 4 (\%0.9)'ünde D. micans'ın faal galerileri tespit edilmiştir (Tablo 1 ). Meşcere kenarında olan ve meşcere kapalılığı içinde bulunan ağaçlar arasında, D. micans zararının devam ettiği ağaçlar bakımından istatistiksel olarak anlamlı bir fark bulunmaktadır (t: 5.019, df: 48, $P<0.05$ ).

Dendroctonus micans'ın faaliyetinin devam ettiği ağaçlarda, $D$. micans'ın 34 ergini, 215 larvası ile birlikte 3 $R$. grandis ergini ve 23 larvası sayılmıştır. D. micans'ın faaliyetinin devam ettiği 39 ağaçtan 34'ünde, böceğin, kabuğu delerek yeni giriş yapmış olan erginleri, geriye kalan 5 ağaçta ise larvaları bulunmuştur. D. micans'ın larva galerilerinin 3 tanesinde $R$. grandis ergini, 2 tanesinde ise yırtıcının larvaları tespit edilmiştir (Tablo 1 ). 
Tablo 1. Dendroctonus micans zararının devam ettiği ağaçlar ile Rhizophagus grandis bulunan ağaçlar, birey sayıları ve örnekleme alanları / transektlerin konumu

\begin{tabular}{|c|c|c|c|c|c|c|c|c|c|c|}
\hline \multirow[t]{2}{*}{$\begin{array}{l}\text { Örnekleme } \\
\text { alanı no }\end{array}$} & \multirow[t]{2}{*}{ Transekt no } & \multirow[t]{2}{*}{ YIl } & \multirow[t]{2}{*}{ Ağaç sayısı } & \multirow[t]{2}{*}{ DMZDEAS } & \multirow[t]{2}{*}{ RGBAS } & \multirow{2}{*}{$\begin{array}{c}\text { Meşcere } \\
\text { kenarındaki } \\
\text { örnekleme } \\
\text { alanları / } \\
\text { Transektler }\end{array}$} & \multicolumn{2}{|c|}{$\begin{array}{l}\text { Dendroctonus } \\
\text { micans }\end{array}$} & \multicolumn{2}{|c|}{$\begin{array}{c}\text { Rhizophagus } \\
\text { grandis }\end{array}$} \\
\hline & & & & & & & Ergin & Larva & Ergin & Larva \\
\hline 1 & & 2014 & 29 & 2 & 1 & + & 1 & 32 & 1 & \\
\hline 2 & & 2014 & 36 & 1 & & + & 1 & & & \\
\hline 3 & & 2014 & 33 & 1 & & + & 1 & & & \\
\hline 4 & & 2014 & 42 & & & & & & & \\
\hline 5 & & 2014 & 28 & & & & & & & \\
\hline 6 & & 2014 & 32 & & & & & & & \\
\hline 7 & & 2014 & 38 & 2 & 1 & + & 1 & 56 & & 9 \\
\hline 8 & & 2014 & 31 & 2 & & + & 2 & & & \\
\hline 9 & & 2014 & 24 & 1 & & + & 1 & & & \\
\hline 10 & & 2014 & 26 & & & & & & & \\
\hline 11 & & 2014 & 22 & 1 & & & 1 & & & \\
\hline 12 & & 2014 & 25 & 1 & & + & 1 & & & \\
\hline 13 & & 2014 & 29 & 2 & & + & 2 & & & \\
\hline 14 & & 2014 & 32 & 3 & 1 & + & 2 & 44 & 1 & \\
\hline \multirow[t]{11}{*}{15} & & 2014 & 24 & 1 & & + & 1 & & & \\
\hline & 1 & 2014 & 18 & & & + & & & & \\
\hline & 2 & 2014 & 20 & 1 & & + & 1 & & & \\
\hline & 3 & 2014 & 16 & & & & & & & \\
\hline & 4 & 2014 & 19 & & & & & & & \\
\hline & 5 & 2014 & 15 & 1 & & + & 1 & & & \\
\hline & 6 & 2014 & 19 & & & & & & & \\
\hline & 7 & 2014 & 20 & 1 & & + & 1 & & & \\
\hline & 8 & 2014 & 20 & 1 & & + & 1 & & & \\
\hline & 9 & 2014 & 15 & & & & & & & \\
\hline & 10 & 2014 & 14 & & & & & & & \\
\hline 16 & & 2015 & 26 & 1 & & & 1 & & & \\
\hline 17 & & 2015 & 25 & 1 & & & 1 & & & \\
\hline 18 & & 2015 & 31 & & & & & & & \\
\hline 19 & & 2015 & 28 & & & & & & & \\
\hline 20 & & 2015 & 25 & 1 & & & 1 & & & \\
\hline 21 & & 2015 & 40 & & & + & & & & \\
\hline 22 & & 2015 & 45 & 2 & 1 & + & 1 & 67 & & 14 \\
\hline 23 & & 2015 & 22 & 1 & & + & 1 & & & \\
\hline 24 & & 2015 & 34 & 1 & & + & 1 & & & \\
\hline 25 & & 2015 & 29 & & & + & & & & \\
\hline 26 & & 2015 & 41 & 1 & & + & 1 & & & \\
\hline 27 & & 2015 & 23 & & & + & & & & \\
\hline 28 & & 2015 & 23 & & & + & & & & \\
\hline 29 & & 2015 & 36 & 3 & 1 & + & 2 & 16 & 1 & \\
\hline \multirow[t]{11}{*}{30} & & 2015 & 28 & 1 & & + & 1 & & & \\
\hline & 11 & 2015 & 16 & & & & & & & \\
\hline & 12 & 2015 & 19 & 1 & & + & 1 & & & \\
\hline & 13 & 2015 & 20 & 2 & & + & 2 & & & \\
\hline & 14 & 2015 & 18 & & & & & & & \\
\hline & 15 & 2015 & 14 & 1 & & + & 1 & & & \\
\hline & 16 & 2015 & 15 & & & & & & & \\
\hline & 17 & 2015 & 18 & & & & & & & \\
\hline & 18 & 2015 & 21 & & & & & & & \\
\hline & 19 & 2015 & 19 & 1 & & + & 1 & & & \\
\hline & 20 & 2015 & 22 & 1 & & + & 1 & & & \\
\hline
\end{tabular}

DMZDEAS: Dendroctonus micans zararı devam eden ağaç sayısı, RGBAS: Rhizophagus grandis bulunan ağaç sayıSı 


\section{TARTIŞMA}

Çalışılan örnekleme alanlarında transektlere oranla daha fazla sayıda ağaç üzerinde $D$. micans zararının devam ettiği ve bu farkın da istatistiksel olarak anlamlı olduğu bulunmuştur. Örnekleme alanlarının \%16.7'sinde $R$. grandis bulunmaktadır. Transektlerde ise $R$. grandis'e rastlanmamıştır. Aynı alanlarda 2000'li yılların başında yapılan çalışmada hem Artvin ve ilçelerinde alınan örnekleme alanlarının tamamında hem de Artvin OіM ladin ormanlarında alınan örnekleme alanlarının tamamında $D$. micans zararının devam ettiği ağaçların bulunduğu kaydedilmiştir. Çalışılan örnekleme alanlarının tamamında $R$. grandis tespit edilmiştir (Alkan-Akıncı 2006).

Çalışmanın ilk yılında $D$. micans zararının devam ettiği ağaçların oranı \%3.3 iken 2015 yılında bu oran \%2.8 olmuştur. Ancak bu fark istatistiksel olarak anlamlı değildir. Bu oran Alkan-Akıncı (2006) tarafından, Artvin ve ilçelerinde \%11.4 ve Artvin OiM ormanlarında \%12,7 olarak kaydedilmiştir. İlk yıl, D. micans zararının devam ettiği ağaçlardan \%14.3'ünde, ikinci yıl ise \%11.1'inde böceğin galerilerinde $R$. grandis tespit edilmiştir. Bu oran Artvin ve ilçelerinde \%41.1 ve Artvin OіM ormanlarında \%57.1'dir (Alkan-Akıncı 2006). Çalışılan örnekleme alanlarında böcek zararının devam ettiği ağaçların oranı ikinci yılda birinci yıla göre daha düşüktür. Bu duruma paralel olarak $R$. grandis tespit edilen ağaçların oranında da bir düşüş gözlemlenmiştir. Artvin ve ilçelerinde $D$. micans zararının devam ettiği ağaçların oranı, Artvin OiM ormanlarındaki orandan daha düşüktür. Benzer şekilde $R$. grandis tespit edilen ağaçların oranı da Artvin ve ilçelerinde daha düşük kaydedilmiştir (Alkan-Akıncı 2006). $R$. grandis'in $D$. micans'ın yoğunluğuna bağlı sayısal tepkisi olduğu bilgisi bu durumu açıklayabilir. Belçika'daki kayıtlarda da $D$. micans zararının daha yüksek olduğu alanlarda predatörün istila oranı yüksek kaydedilmiştir (Grégoire 1988).

Incelenen tüm ağaçlar birlikte değerlendirildiğinde, ağaçların \%3.1'inde $D$. micans'ın faaliyetinin devam ettiği ve bu ağaçlardan $\% 12.8^{\prime}$ inde $R$. grandis bulunduğu belirlenmiştir. Böceğin zarar oranı, 2000'li yılların başına göre 4.1 kat, $R$. grandis' in tespit edildiği ağaçların oranı ise 4.4 kat daha azdır.

Meşcere kenarında bulunan örnekleme alanlarında ve transektlerdeki ağaçlardan $D$. micans zararına uğrayanların oranı, hem meşcere kapalılığı içinde yer alan ağaçlardan hem de toplam ağaçlar içerisinde böceğin zararına uğrayanların yüzdesinden daha fazladır. Ve bu fark istatiksel olarak ta anlamlı bulunmuştur. D. micans'ın meşcere kenarındaki ağaçlara saldırdığı daha önce de kaydedilmiştir (Granet ve Perrot 1977). Bu alanların meşcere içine oranla daha fazla güneş ışığı alması böceğin gelişimi için avantajlı olacaktır

Rhizophagus grandis D. micans'ın larva galerilerinin tamamında tespit edilmiştir. $D$. micans'ın galeri sistemlerinin, böceklerin gelişimi süresince $R$. grandis'e karşı cezbediciliğini sürdürdüğü bilinmektedir. Yumurta galerilerinin cezbediciliğinin muhtemelen ergin kabuk böcekleri tarafından üretilen kimyasallardan kaynaklandığı, daha ileri dönemlerdeki sistemlerin cezbediciliğinin ise $D$. micans larvalarının ürettiği kimyasallardan kaynaklandığı kaydedilmiştir (Grégoire ve ark. 1989).

Sonuç olarak, D. micans'ın Artvin ladin ormanlarında, Grégoire (1984) ve Grégoire ve ark. (1989)'da belirtilen "çok düşük istila" oranına sahip olduğu ve böceğin ağaçlardaki istila yüzdesinin 2000'li yılların başına oranla azaldığı tespit edilmiştir. Meşcere kenarında bulunan ağaçlar daha fazla böcek zararına uğramıştır. D. micans'ın larva galerilerinin tamamında $R$. grandis tespit edilmiştir. Böceğin ormanlardaki zararı düşük seviyede olduğunda da $R$. grandis'in avının larva galerine yerleşebildiği görülmüştür. Böceğin uzun yıllardır salgınlar oluşturarak ekonomik kayıplara neden olduğu Avrupa'da pek çok faktörün $D$. micans'ın populasyonunun düşmesiyle ilişkili olabileceği tartışımaktadır. Normal klimatik koşulların geri dönmesi büyük olasılıkla zorunlu bir önkoşuldur ve bakım kesimleri, temizlik kesimleri gibi insan aktiviteleri ve karantina önlemleri muhtemelen katkı sağlamaktadır. Aynı ağaç üzerindeki galeriler arasındaki türiçi rekabet yüksek populasyon yoğunluklarında devreye girmektedir. Özellikle $R$. grandis gibi doğal düşmanlar da önemli olmuştur (Grégoire 1988). 


\section{KAYNAKLAR}

Acatay A (1968) Türkiye'de Yeni Bir Ladin Tahripçisi, Dendroctonus micans Kug. I.Ü. Orman Fakültesi Dergisi 18 (1): 18-36.

Aksu Y (2011) Rhizophagus grandis Gyll. (Coleoptera: Rhizophagidae)'in biyolojisi, laboratuvarda üretim yöntemleri, ormanlara salınması ve mücadele sonuçları. Türkiye I. Orman Entomolojisi ve Patolojisi Sempozyumu, 23-25 Kasım 2011, Antalya, pp 73-79.

Aksu Y, Dedeağaoğlu C, Çelik B (2014) Dendroctonus micans (Kug) (Coleoptera: Scolytidea)'ın mücadelesinde kullanılan Rhizophagus grandis (Gyll) (Coleoptera: Rhizophagidae)'ın kutu metodu ile üretilmesi. Türkiye II. Orman Entomolojisi ve Patolojisi Sempozyumu, 7-9 Nisan 2014, Antalya, pp 64-71.

Alkan ş (1989) Dendroctonus micans (Kug.)'la Savaş (Dünü, Bugünü, Yarını). Orman Mühendisliği Dergisi 4, 30.

Alkan Ş (2000) Ladin ormanlarına zarar veren Dendroctonus micans ve Ips typographus zararlılarına karşı sürdürülen mücadele uygulamaları, Eğitim Semineri, 22-26 Mayıs, İstanbul, pp 10-18.

Alkan-Akıncı H (2006) Doğu Ladini Ormanlarında Dendroctonus micans (Kugelann)'ın Populasyon Dinamiğine Etki Eden Etmenler ve Ips typographus (Linnaeus) ile Diğer Kabuk Böceği Türleri (Coleoptera, Scolytidae)'nin Populasyon Düzeyleri ve Etkileşimleri. Doktora Tezi, Karadeniz Teknik Üniversitesi.

Alkan-Akıncı H, Eroğlu M, Özcan GE (2014) Attack strategy and development of Dendroctonus micans (Kug.) (Coleoptera: Curculionidae) on oriental spruce in Turkey. Turkish Journal of Entomology 38(1): 31-41.

Alkan-Akıncı H, Grégoire JC (2016) Preliminary results of the observations on oviposition and predation impact of Rhizophagus grandis Gyll. (Coleoptera: Monotomidae) on Dendroctonus micans (Kug.) (Coleoptera: Curculionidae) in Turkey. Proceedings of International Forestry Syposium, 7 - 10 December 2016, Kastamonu, pp $16-21$.

Alkan-Akıncı H, Özcan GE, Eroğlu M (2009) Impacts of site effects on losses of oriental spruce during Dendroctonus micans (Kug.) outbreaks in Turkey. African Journal of Biotechnology 8(16): 39343939.

Eroğlu M (1995) Dendroctonus micans (Kug.) (Coleoptra, Scolytidae)'ın Populasyon Dinamiğine Etki Eden Faktörler Üzerine Araştırmalar. I. Ulusal Karadeniz Ormancılık Kongresi Bildirileri, 23-25 Ekim 1995, Trabzon, 3. Cilt, pp 148-159.
Eroğlu M, Alkan-Akıncı H, Keskin S (2010) Ladin ormanlarımızda Dendroctonus micans (Kugelann)'ın biyolojik mücadelesinde doğal denge. Tabiat ve İnsan 44, $11-18$.

Fielding NJ, Evans H (1997) Biological control of Dendroctonus micans (Scolytidae) in Great Britain. Biocontrol News and Information 18 (2): 51-60.

Granet AM, Perrot JM (1977) Dendroctonus micans Kug. dans le sudest du Massif central. Aires d'extension et premier essai d'interprétation des dommages. Mémoire de 3éme année, Ecole Nationale Des Ingénieurs Des Travaux Des Eaux Et Forêts, Les Bars, France, 127.

Grégoire JC (1984) Dendroctonus micans in Belgium: The situation today. Proceedings of the EEC Seminar Biological Control of Bark Beetles (Dendroctonus micans), 3-4 October 1984, Brussels, Belgium, pp 48-62.

Grégoire JC (1985) Host colonization strategies in Dendroctonus: Larval gregariousness or mass attack by adults? In: Safranyik LS (ed) The Role of the Host in the Population Dynamics of Forest Insects, pp 147-154.

Grégoire JC (1988) The Greater European Spruce Beetle. In: Berryman AA (ed) Dynamics of Forest Insects Populations, Plenum Press, New York, pp 455-478.

Grégoire JC, Baisier M, Merlin J, Naccache Y (1989) Interactions between Rhizophagus grandis (Coleoptera: Rhizophagidae) and Dendroctonus micans (Coleoptera: Scolytidae) in the field and the laboratory: their application for the biological control of $D$. micans in France. In: Kulhavy D and Miller MC (ed) The Potential for Biological Control of Dendroctonus and Ips Bark Beetles, The Stephen Austin University Press, Nagocdoches, pp 95-108.

King CJ, Fielding NJ, O'Keefe T (1991) Observation on the life cycle and behavior of the predatory beetle, Rhizophagus grandis Gyll. (Col., Rhizophagidae) in Britain. Journal of Applied Entomology 111: 286-296.

Khobakhidze DN, Tvaradze MS, Kraveishvili IK (1970) Preliminary results of introduction, study of bioecology, development of methods of artificial rearing and naturalization of the effective entomophage, Rhizophagus grandis Gyll., against the European spruce beetle, Dendroctonus micans Kugel., in spruce plantations in Georgia. Bulletin of the Academy of Sciences of the Georgian SSR 60: 205-208.

Serez M, Keskinalemdar E, Aksu Y, Alkan Ş (1987) Rhizophagus grandis Gyll. (Coleoptera, Rhizophagidae)'in Laboratuarda Üretimi ve Dendroctonus micans Kug.'a Karşı Kullanılma Olanakları. KTÜ Orman Fakültesi Dergisi 10 (1-2): 3-11. 